\title{
Autosomal Dominant Inheritance and Amino Aciduria in Blackfan-Diamond Anaemia*
}

\author{
MARIA L. FALTER and MARGARET G. ROBINSON \\ From the Department of Pediatrics, State University of New York, Downstate Medical Center, \\ Brooklyn, New York, USA
}

Since congenital hypoplastic anaemia was first described by Diamond and Blackfan in 1938, over a hundred cases have been reported in the literature. The syndrome is characterized by a profound persistent anaemia, onset early in infancy, a severe hypoplasia of the erythroid precursors of the bone marrow, and absence of other haematological abnormalities. Until steroids become available for treatment, the anaemia was resistant to all forms of therapy, the life of the child depending upon transfusions. In some children spontaneous permanent remissions have been described. In a few patients, following a spontaneous remission, recurrence of the anaemia again necessitated transfusions (von Sydow, 1943; Diamond, Allen, and Magill, 1961).

The aetiology of the disease is not known. Diamond et al (1961) suggested an inborn error of metabolism of some unknown blood-building substance essential to normal erythropoiesis. In support of this theory, Altman and Miller (1953) reported excessive accumulation of anthranilic acid and other tryptophan metabolites in the urines of patients with congenital hypoplastic anaemia. Pearson and Cone (1957) and Marver (1961) confirmed these findings, but Smith et al (1960), Harvey (1966), and Price et al (1969) found no consistency in tryptophan metabolite excretion in patients they tested. Gilman and Howell (1969) reported a case of Blackfan-Diamond anaemia associated with histidinaemia, but assumed that the occurrence of the two conditions was coincidental.

Although Blackfan-Diamond anaemia usually occurred as a single incident in a family, the observation of two or more affected sibs in several families suggested the possibility of a genetic pattern. The mode of inheritance was never clearly defined. It was assumed to be autosomal recessive. Förare

Received 30 July 1971.

* This investigation was supported by a Public Health service research grant No. 5R01-HD02472 from the National Institutes of Child Health and Human Development.
(1963) was the first to report Blackfan-Diamond anaemia in 2 children having the same father but born by different mothers. Mott, Apley, and Raper (1969) described an analogous situation in which 3 children with this syndrome were conceived by 2 different women from the same father. These two observations suggested that the disease was transmitted by a single dominant gene which was not expressed in the clinically healthy fathers.

Our report describes a negro woman with Blackfan-Diamond anaemia who gave birth to a girl affected with the same disease. To our knowledge this is the first incidence of direct transmission from mother to child and supports the autosomal dominant mode of inheritance of congenital hypoplastic anaemia. An additional interesting finding was an increased plasma level and urinary excretion of multiple amino acids in the mother. No such abnormalities could be found in the child.

\section{Methods}

Standard haematological methods were used. The amino-acid contents of plasma and urine were analysed by use of an amino-acid analyser built according to the modification of Piez and Morris (1960) of the technique originally described by Spackman, Stein, and Moore (1958). Loading tests were performed with L-tryptophan $100 \mathrm{mg} / \mathrm{kg}$, glycine $100 \mathrm{mg} / \mathrm{kg}$, proline $100 \mathrm{mg} / \mathrm{kg}$, and hydroxyproline $100 \mathrm{mg} / \mathrm{kg}$.

\section{Case Reports}

Case 1. S.R., a 17-year-old negro female was first seen at Kings County Hospital in January 1966. She gave a history of severe, chronic anaemia for which she had had many hospital admissions and multiple transfusions (every 2 weeks according to her memory) during the first 6 years of life. About that time the need for transfusions subsided. One year later, upon readmission to the same hospital for a fractured wrist due to trauma, she was found to be anaemic. Although no transfusions were required, she was kept in the hospital 
for a year while being treated with 'green pills'. She continued taking the 'green pills' for the next 7 years when she stopped attending the clinic. A year later, when admitted to a State Hospital for truancy, she was found to be quite anaemic and received blood transfusions every 3 to 4 weeks for more than a year. Following discharge from the State Hospital, she was transferred to Kings County Hospital for investigation of her chronic anaemia.

On admission the patient was not in distress. The physical examination revealed no abnormalities. There was no pallor nor any hyperpigmentation of the skin. The liver and the spleen were not enlarged.

On admission haemoglobin was $12.2 \mathrm{~g} \%$ (post transfusion); hematocrit, $38 \%$; RBC, 3.7 millions $/ \mathrm{mm}^{3}$; MCV, $103 \mu^{3} ; \mathrm{MCH}, 33 \gamma \gamma ; \mathrm{MCHC}, 32 \%$; reticulocyte count, $0 \cdot 1 \%$; WBC, $8600 / \mathrm{mm}^{3}$ with a normal differential. Platelets were adequate on the peripheral blood smear. The Coombs test was negative. Haemoglobin electrophoresis revealed a normal haemoglobin AA pattern with an increased fetal haemoglobin of $7.7 \mathrm{~g} \%$; the serum iron was $242 \mu \mathrm{g}^{\circ}$; and the unsaturated iron-binding capacity was $53 \mu \mathrm{g}_{0}^{\circ}$. Liver function tests were normal. Chest radiology at admission and 2 subsequent chest $x$-rays were normal.

A bone marrow biopsy showed a normocellular marrow with mostly granulocytic precursors and very few normoblasts. Megakaryocytes were present and normal in number and morphology. Ferrokinetic studies with ${ }^{59} \mathrm{Fe}$ showed a decreased plasma iron clearance and a decreased incorporation of iron into the erythrocytes. A diagnosis of Blackfan-Diamond anaemia was made on the basis of her past medical history and the above laboratory data.

During the 6 weeks the patient remained in the hospital, her haemoglobin decreased an average of $1.2 \mathrm{~g} \%$ per week necessitating 2 transfussions. One month after discharge she became pregnant. Since then her haemoglobin has remained fairly stable fluctuating between 11.0 and $14.0 \mathrm{~g}_{\%}^{\circ}$. A repeat serum iron performed in January 1967 was $236 \mu \mathrm{g} \%$ and the unsaturated iron-binding capacity was $206 \mu \mathrm{g} \%$. She has been on no medications except contraceptive drugs since her baby's birth.

The patient also gave a history of periodic seizures which, since their onset when she was aged 7 to 8 years, alternated with intervals free of seizures. An EEG showed bitemporal slow waves in paroxysmal fashion. The diagnosis of a mixed convulsive disorder was made.

Special laboratory tests (performed December 1969). Urine examinations did not show increased excretion of tryptophan metabolites. Amino-acid analysis of the urine showed marked increases of glycine, threonineserine, lysine, and histidine. The blood levels of the following amino acids were considerably elevated on repeated testing: glutamine, alanine, lysine, arginine, and threonine-serine. An inconsistent elevation of proline, valine, leucine, and ornithine was also found. Blood levels of glycine and cystine were normal. Loading tests with glycine, proline, and hydroxyproline demonstrated no abnormality in gastrointestinal absorption.
Plasma levels of the amino acids reached good peaks and except for proline returned to normal after 2-4 hours. After 6 hours the proline concentration in the plasma was still $10 \mathrm{mg} \%$ (base line $2.55 \mathrm{mg} \%$, normal $2.4 \% \pm$ $0 \cdot 16$ ). The multiple amino-acid abnormalities in this patient are still under investigation.

Case 2. R.R., the daughter of S.R., was born on 10 February 1967 after a 38-week gestation and weighed $1860 \mathrm{~g}$. The Apgar score was 8 after one minute. No physical abnormalities were present. The haemoglobin at birth was $12.5 \mathrm{~g} \%$; the reticulocyte count, $1.5 \%$; white blood cell and platelet counts were normal. Because of the maternal history and the infant's inability to maintain her haemoglobin, a bone marrow aspiration was performed. This aspirate showed a myeloid:erythroid ratio of $5: 1$. When she was 18 days old, she received the first transfusion. Until her discharge from the hospital at age $5 \frac{1}{2}$ weeks she required three transfusions.

We saw the patient for the first time when she was 6 weeks old. The physical examination was normal. Haemoglobin was $9.0 \mathrm{~g} \%$; reticulocyte count, $0.3 \%$; white blood cells, $5400 / \mathrm{mm}^{3}$ with a normal differential count; platelet count, $150,000 / \mathrm{mm}^{3}$. The bone marrow revealed marked erythroid hypoplasia with a $M: E$ ratio of $46: 1$ and a maturation arrest at the level of the basophilic normoblasts. Chromosome studies showed a normal chromosomal pattern.

Prednisone therapy $(15 \mathrm{mg} /$ day $)$ was started at the age of 8 weeks. A good reticulocyte response with a rise in haemoglobin and maintenance of normal values was obtained. Following this, the dose of prednisone was gradually lessened to $2.5 \mathrm{mg} /$ day. For 5 weeks the child did not return to clinic. When we saw the baby again, the haemoglobin had dropped to $5.0 \mathrm{~g} \%$, and the reticulocyte count was $0 \cdot 1 \%$. The mother admitted to discontinuing the medication. The baby was admitted, transfused and restarted on prednisone $(20 \mathrm{mg}$ / day). An excellent response with a rise in the reticulocytes, followed by an increase in haemoglobin was again observed. Since then the baby has maintained a haemoglobin between 10.0 and $11.0 \mathrm{~g} \%$ on a maintenance dose of prednisone $(7.5 \mathrm{mg} /$ day). Physical, motor, and mental development have progressed normally, although the child is of small stature (10th centile) as is her mother. Amino-acid studies performed while she was off prednisone therapy showed normal plasma and urine levels. Tryptophan, glycine, and proline loading tests gave normal results.

\section{Family Investigation}

Eleven other members of the family, comprising 5 generations were evaluated for haematological and aminoacid abnormalities. Two females had mild iron deficiency, and 4 had positive sickle cell preparations. There were no morphological abnormalities of the red cells; white cells and platelets were normal. Screening tests for plasma and urine amino acids did not reveal any abnormal values. 


\section{Discussion}

More than 30 years ago congenital hypoplastic anaemia was recognized as an entity. Since then the search for the aetiology was hampered by the rarity of the disease and the even rarer familial occurrence of the syndrome. There is only one report in the literature (Wallman, 1956) where the anaemia was directly transmitted from father to daughter. The onset of the disease was rather late in life in both individuals (34 years and 6 years respectively), and therefore the important criterion of onset in early infancy was not met. But all other characteristics for the diagnosis were present. From the observations of Förare (1963) and Mott et al (1969), observations in which two apparently healthy fathers had anaemic children each from 2 different women, it became apparent the BlackfanDiamond anaemia was a genetically determined disease, transmitted as an autosomal dominant. In the fathers, who were heterozygous carriers, the gene remained unexpressed. Mott et al (1969) attributed this to a profound modification of the gene in certain persons. They postulated that the gene survives because of a sex modification in the male carrier who does not experience its ill effects. This hypothesis seems to be supported by the fact that in general boys are less severely affected than girls (Mott et al, 1969) and there is a general preponderance of afflicted females (Jeune et al, 1954).

The present report is the first observation of transmission of the disease from mother to daughter, further supporting the hypothesis that the disorder is inherited as an autosomal dominant. The clinical course of the mother is unusual. She experienced one of the rather rare spontaneous remissions when she was 7 years old with a temporary recurrence of the anaemia of about one year's duration during puberty. Clinically she has no evidence of haemosiderosis in spite of frequent transfusions during her childhood. The associated abnormality in the metabolism of multiple amino acids is also of interest. The disorder was not transmitted to the child, and a causal relationship between the two rare conditions can not be postulated.

Blackfan-Diamond anaemia can now be successfully treated with steroids, eliminating the need for transfusions and the subsequent haemosiderosis. More patients can be expected to enter reproductive age. Studies on their offspring will be of importance in obtaining more genetic information about this rare disease.

\section{Summary}

Direct transmission of Blackfan-Diamond anaemia from mother to daughter is described for the first time. This gives further proof that the condition is inherited as an autosomal dominant character. The occurrence of a multiple amino-acid disorder in the mother and not in the daughter suggests that there is no causal relationship between the two diseases.

We are grateful to Dr Rosemarie Thau, Dr Salvador Castells and Dr Savita Inamdar for performing aminoacid analyses and to Mr Vernon Delgado for technical assistance. We express our appreciation to Dr Dorothy Holden (Department of Medicine, Downstate University Medical Center) for the abstract of the history on case 1 .

\section{REFERENCES}

Altman, K. I. and Miller, G. (1953). A disturbance of trytophan metabolism in congenital hypoplastic anemia. Nature (London), $172,868$.

Diamond, L. K. and Blackfan, K. D. (1938). Hypoplastic anemia. American Fournal of Diseases of Children, 56, 464-467.

Diamond, L. K., Allen, D. M., and Magill, F. B. (1961). Congenital (erythroid) hypoplastic anemia. A 25 year study. American Fournal of Diseases of Children, 102, 403-415.

Förare, S. A. (1963). Pure red cell anemia in step siblings. Acta Pediatrica, 52, 159-160.

Gilman, P. A. and Howell, R. R. (1969). The simultaneous occurrence of histidinemia and congenital hypoplastic anemia. Fournal of Pediatrics, 75, 878-880.

Harvey, D. R. (1966). Congenital hypoplastic anemia. Proceedings of the Royal Society of Medicine, 59, 490-492.

Jeune, M., Revol, L., Larbre, F., and Loaec, Y. (1954). La maladie de Diamond et Blackfan, anémie par erythrogénèse imparfaite. Pédiatrie, 9, 461-480.

Marver, H. S. (1961). Studies on tryptophan metabolism. Urinary tryptophan metabolites in hypoplastic anemias and other hematological disorders. Fournal of Laboratory and Clinical Medicine, 58, 425-436.

Mott, M. G., Apley, J., and Raper, A. B. (1969). Congenital (erythroid) hypoplastic anaemia: Modified expression in males. Archives of Disease in Childhood, 44, 757-760.

Pearson, H. A. and Cone, T. E., Jr. (1957). Congenital hypoplastic anemia. Pediatrics, 19, 192-200.

Piez, K. A. and Morris, L. (1960). A modified procedure for the automatic analysis of amino acids. Analytical Biochemistry, 1, 187-201.

Price, J. M., Brown, R. R., Pfaffenbach, E. C., and Smith, N. J. (1969). Excretion of urinary tryptophan metabolites by patients with congenital hypoplastic anemia (Diamond-Blackfan syndrome). Fournal of Laboratory and Clinical Medicine, 75, 316-324.

Smith, N. J., Price, J. M., Brown, R. R., and Moon, R. L., (1960). Urinary excretion of tryptophan metabolites by patients with congenital hypoplastic anemia. American fournal of Diseases of Children, 100, 752-753.

Spackman, D. H., Stein, W. H., and Moore, S. (1958). Automatic recording apparatus for use in the chromatography of amino acids. Analytical Chemistry, 30, 1190-1206.

Sydow, G. von (1943). Hypoplastic anemia. Acta Paediatrica, 30, 365-387.

Wallman, I. S. (1956). Hereditary red cell aplasia. Medical Fournal of Australia, 2, 488-490. 